\title{
Analysis of Students' Error in Solving Trigonometric Function Problems which Assess Higher Order Thinking Skills
}

\author{
Ika Sartika $^{1 *}(\mathbb{D})$, Namirah Fatmanissa ${ }^{1} \mathbb{D}$
}

${ }^{1}$ Sampoerna University, INDONESIA

*Corresponding Author: sartikaika160313@gmail.com

Citation: Sartika, I., \& Fatmanissa, N. (2020). Analysis of Students' Error in Solving Trigonometric Function Problems which Assess Higher Order Thinking Skills. Contemporary Mathematics and Science Education, 1(1), ep20002. https://doi.org/10.30935/conmaths/8437

\begin{abstract}
International survey, such as TIMSS and PISA have indicated that higher order thinking skills (HOTS) of Indonesian students is still low. The purpose of this study is to identify students' error in solving trigonometric function problem which assess HOTS. This is a case study research with a qualitative descriptive approach, in which the participants were all students of class IX A Science Program at SMAN X Karawang, East Karawang, Indonesia. Data was collected using test to identify students' error in solving trigonometric problems which assess HOTS, which was develop based on the basic competence of high school mathematics and Bloom taxonomy. Beside conducting the test, the data also was collected from the interview result, where the interview will focus on the students that has low, medium, and high score on the test. Students' errors were classified based on Newman's Error Analysis. The result of the study revealed that the students' errors found were comprehension error, transformation error, and process skill error.
\end{abstract}

Keywords: higher order thinking, trigonometric functions, students' error

Received: 1 Jun. 2020 Accepted: 12 Jul. 2020

\section{INTRODUCTION}

Higher Order Thinking Skill (HOTS) is an important aspect of the teaching and learning process, because it is appropriate with the teaching goal, which is to make sure the students thinking and solve the problems critically (Chidozie et al., 2014). As the definition of HOTS by two disciplines: philosophy and psychology, HOT is a thinking skill which involves problem solving and critical thinking (Lewis \& Smith, n.d.), so the students trained to solve a real life and complex problem. Taken from Bloom's Taxonomy revision proposed by Anderson and Krathwohl (2001), HOTS has three levels of upper-level cognitive skills that are hierarchical, which are analyzing, evaluating, and creating. Means, the students cannot jump or skip the levels freely because each level has a sub-category to describe its objective (Stayanchi, 2017). Because this is important, Indonesia government implements curriculum 2013 (newest version 2016) as the educational system that focuses on the development of HOTS (Ministry of Education and Culture, 2016). One of the government's ways to develop HOTS is incorporating HOTS in the examination.

However, in 2015 an international survey indicated that Indonesian students' HOTS is still low (OECD, 2016). Some studies have investigated the difficulties in solving problem especially mathematics problems which assess HOTS were faced by the students in high school (Hadi et al., 2018). It is supported by students' complaining to the government about their anxiety in solving mathematics problem that assess HOTS in National Examination (Ardina, 2018). Moreover, Fi (2003) stated that many researchers found the difficulties often occurs in trigonometric functions, especially sinus, cosines, and domain. These difficulties are caused by the errors. One of the example errors that was found in Fi's study was incorrectly placing law of cosines. As Abdullah et.al (2015) stated, the students made various of errors because they found it difficulties to solve the questions. Meanwhile, White (2005) said, error can happen at any time, so error analysis is important to avoid causing errors.

Such difficulties also occurred in one of public senior high schools that uses curriculum 2013 in Karawang. In 2017, the Ministry of Education and Culture indicated that the students' National Examination results in this school are low. It is proved by the lowest average score of mathematics being 33.03 (“Sekolah Kita," n.d.). By taking all those facts into account, it is urgent to investigate the students' error in solving trigonometric function problem which assess HOTS.

\section{HIGHER ORDER THINKING}

Higher Order Thinking Skills (HOTS) is said as a high level of thinking because it needs hard effort and produces valuable outcomes, but the process of HOT is not mechanical, so these outcomes are not predictable and hard to define (Wegerif, 2002). Nevertheless, many experts tried to define HOTS with different approaches and viewpoints. In the past, two disciplines contributed to interpreting HOTS based on 
Table 1. Description and Keywords of Bloom's Taxonomy Revision

\begin{tabular}{|c|c|c|}
\hline Category \& Cognitive Progress & Keywords & \\
\hline Remembering: Retrieve relevant knowledge from long-term memory & Identifying, retrieving & \multirow{2}{*}{$\begin{array}{l}\text { LOTS - Lower Order } \\
\text { Thinking Skills }\end{array}$} \\
\hline $\begin{array}{l}\text { Understanding : Construct meaning from instructional messages, } \\
\text { including oral, written, and graphic communication. }\end{array}$ & $\begin{array}{l}\text { Clarifying, paraphrasing, representing, translating, Illustrating, } \\
\text { instantiating, categorizing, subsuming, abstracting, abstracting, } \\
\text { generalizing,concluding, extrapolating. interpolating. predicting, } \\
\text { contrasting, mapping, matching, constructing models }\end{array}$ & \\
\hline Applying : Carry out or use a procedure in a given situation. & Carrying out, using & \\
\hline $\begin{array}{l}\text { Analyzing: Break material into its constituent parts and determine } \\
\text { how the parts relate to one another and to an overall structure or } \\
\text { purpose }\end{array}$ & $\begin{array}{l}\text { Discriminating, distinguishing, focusing, selecting, finding, } \\
\text { coherence. integrating, outlining, parsing, structuring, } \\
\text { deconstructing }\end{array}$ & \multirow[t]{3}{*}{$\begin{array}{l}\text { HOTS - Higher } \\
\text { Order Thinking } \\
\text { Skills }\end{array}$} \\
\hline Evaluating: Make judgments based on criteria and standard & Coordinating. detecting, monitoring, testing, judging & \\
\hline $\begin{array}{l}\text { Creating: Put elements together to form a coherent or functional } \\
\text { whole; reorganize elements into a new pattern or structure }\end{array}$ & Hypothesizing, designing, constructing & \\
\hline
\end{tabular}

(Anderson and Krathwohl, 2001)

Table 2. Subtopics of Trigonometric Functions in Curriculum 2013

\begin{tabular}{ll}
\hline Grade & Subtopic \\
\hline 10 & - Trigonometric functions using graph. \\
& - Graph of trigonometric functions. \\
\hline 11 & - \\
\hline 12 & - Graph of trigonometric functions \\
& - Limit of trigonometric functions \\
\hline
\end{tabular}

their perspective: philosophy and psychology (Lewis and Smith, 1993). The philosophy perspective believes that HOTS is a process of learning that emphasizes critical thinking, while physiology perspective defines HOTS as problem-solving. Although problem-solving and critical thinking are part of thinking skills, but they think, critical thinking is not problem-solving because it does not cover all term for all thinking skills.

Besides those disciplines, HOTS is also defined by other experts. According to Heong, et al. (2011), HOTS is thinking processability to find new challenge widely. HOTS encouraged people to apply the information that they just learned and operate that information to find out the possibility of the answer in a new situation with the strategies that they used. It is strengthened by Lewis and Smith (1993) define HOTS as a term that has a meaning more than problem-solving, creative thinking, critical thinking, and decision making.

According to the thinking skills framework, HOTS is often interpreted as a cognitive process. Krathworl (2002) said, the indicators to measure HOTS is using Bloom's Taxonomy. HOTS referring Bloom's Taxonomy consists of analyzing, evaluating, and creating. The description and keywords of Bloom's Taxonomy can be seen in Table 1.

\section{TRIGONOMETRIC FUNCTION}

Trigonometric functions are operations that cannot be indicated as an algebraic formula where students do not need to consider it as a function (Breidenbach, Dubinsky, Hawk, \& Nichols, 1992). Andregg and Roe (1896) illustrated trigonometric functions as six primary trigonometric functions (sine, cosine, tangent, cotangent, secant, cosecant). These ratios can be formed by using triangle with three sides and the angle is known.

In Indonesia context, trigonometric function topics were given to grade 10 and 12 as shown in Table 2. It shows that the subtopics in grade 10 are more focused on basic of trigonometric functions and how

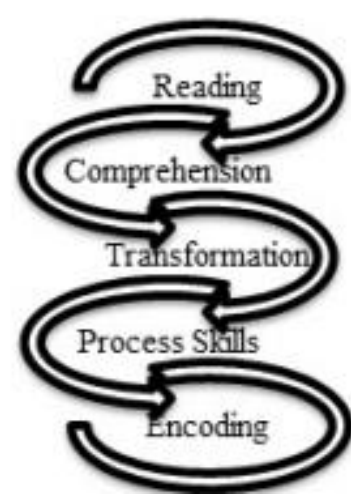

Figure 1. The Newman's Error Analysis Model

to make a graph from the function that is given. However, in grade 11, the students did not learn trigonometric functions, but it is introduced again in grade 12 with the complex concept where the limit $x$ approaches a value appeared.

\section{STUDENTS' ERROR}

Error is defined as something done wrong (Erdogan, 2005), where the learner uses incorrect form and unable to get the correct form. Based on Spooner (2002), an error occurs due to the carelessness, that usual appears from the misinterpretation and lack of knowledge. Newman (1977) investigated an error was not only caused by the carelessness but also caused by lack of motivation. The fact of students' error is called as error analysis.

The simple model that applicable to measure the students' errors is Newman Error Analysis (NEA) (Prakitipong \& Nakamura, 2006; Effandi Zakaria \& Siti Mistima, 2010). This model can be used to determine the students' errors in solving mathematical problem which assess HOTS, means it is fit with this study. According to Newman (1977), there are five categories of error, which are reading errors, comprehension errors, transformation errors, process skills errors, and encoding errors, it is shown in Figure 1.

The first category is reading error, which the student's inability to read the text and symbols. Comprehension errors are the error in understanding the given information of the problem. The next is transformation error, which an error in transforming the visual mathematics into mathematics representation include solution 


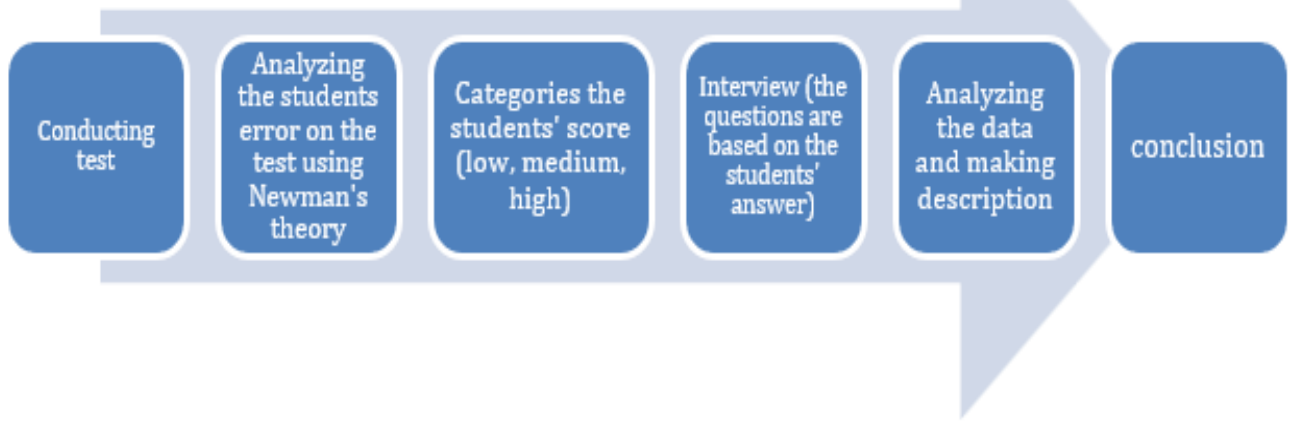

Figure 2. Procedure of the research

strategies. Process skills error is an error in referring to the mistake of calculating mathematical processes to get the correct result and recognizing the operation. Lastly, encoding error is an error made by the students when explaining the conclusion. In this study, NEA was used to identify the students' error.

\section{METHODOLOGY}

This study used a qualitative descriptive method as its research design whereby the objective is to present comprehensive summaries of an event (this case is the identification of students' errors in solving trigonometric function which assess HOTS) experienced by a group of people. By using this method, researchers tend to analyze the data or information in any interpretive depth (Sandelowski, 2000). Means, the study will gain rich qualitative data rather than only score or number. Figure 2 provides an outline of the procedure of this research.

The participants were 34 students of $12^{\text {th }}$ graders in Science Program in one of public high schools in Karawang, Indonesia. According to the curriculum 2013, the national curriculum which the school uses for teaching mathematics, all students have learned about trigonometric function since 10th grade. In addition, the participants and sites in qualitative research are chosen by using purposive sampling, meaning the researcher see and select the sample based on their involvement with the studied phenomenon, i.e. errors in solving problems that require HOTS.

All participants were given an essay test that consisted of 4 nonroutine problems about trigonometric function. After that, six students were chosen to be the interview subject of the study. They were selected based on their score result of the test that was classified into three levels: high, medium, and low. The first (Q1) and second student (Q2) were the students with the lowest score; the third (Q3) and fourth student (Q4) were the students with average scores; and the fifth (Q5) and sixth student (Q6) were the students with the highest score on the test.

The researcher collected the data by using test and interview. The instrument of the test was developed considering two aspects. The first one is the sub-topic of trigonometric function. The test is divided by two subtopics, which are graphing and proving identities (see Table 3 ). The second aspect is the level of Bloom Taxonomy. Each trigonometry sub-topic had problem of analysis level and evaluation level. Trigonometry sub-topics were based on the Basic Competences and the textbook that was provided by the government. The test was nonroutine problem and already validated by the mathematics experts.
After conducting the test, the researcher interviewed six students who have low, medium, and high scores on the test. This interview aimed to know deeper about the students' strategies and the errors that they faced based on their perspective. The interview questions referred to interview procedure of Newman Error Analysis. The questions were given with more detail in Table 4. By using students' responses to the test and interview, then the errors were identified through analyzing the responses.

\section{RESULT}

The researcher collected the data of the students' errors in solving trigonometric function which assess HOTS test items by using Newman's Error Analysis (NEA). The summary of the students' test general result can be seen on the Table 5. The table shows that the students have difficulties in solving the problems. It was proven by the low number of students with correct answers and the high number of students who either did not answer or got an incorrect answer. Based on the table, problem 3 is considered as the prime problem in which none students got the correct answer. While the most incorrectly answered problems are problem 1 and problem 4.

The errors found in the incorrect answers then were categorized into five types of error, i.e. reading errors, comprehension errors, transformation errors, process skills errors, and encoding errors (see Table 6). It shows that reading errors and encoding errors are not found in the subjects' results. Reading errors are a mistake made by the students in reading the symbols written and keywords on the problem. This could be understood since the participants are high school students, thus they did not have difficulties in reading the text. Also, encoding errors are a mistype made by the students at the final result. In encoding errors, the students correctly solve the problem with the right strategy but failed to express the conclusion. This error is not found because the students did write their own intended answer correctly.

\section{Comprehension Error}

Comprehension errors occur when the students unable to write down the relevant information given or do not understand the 
Table 3. Non-routine problems on the test

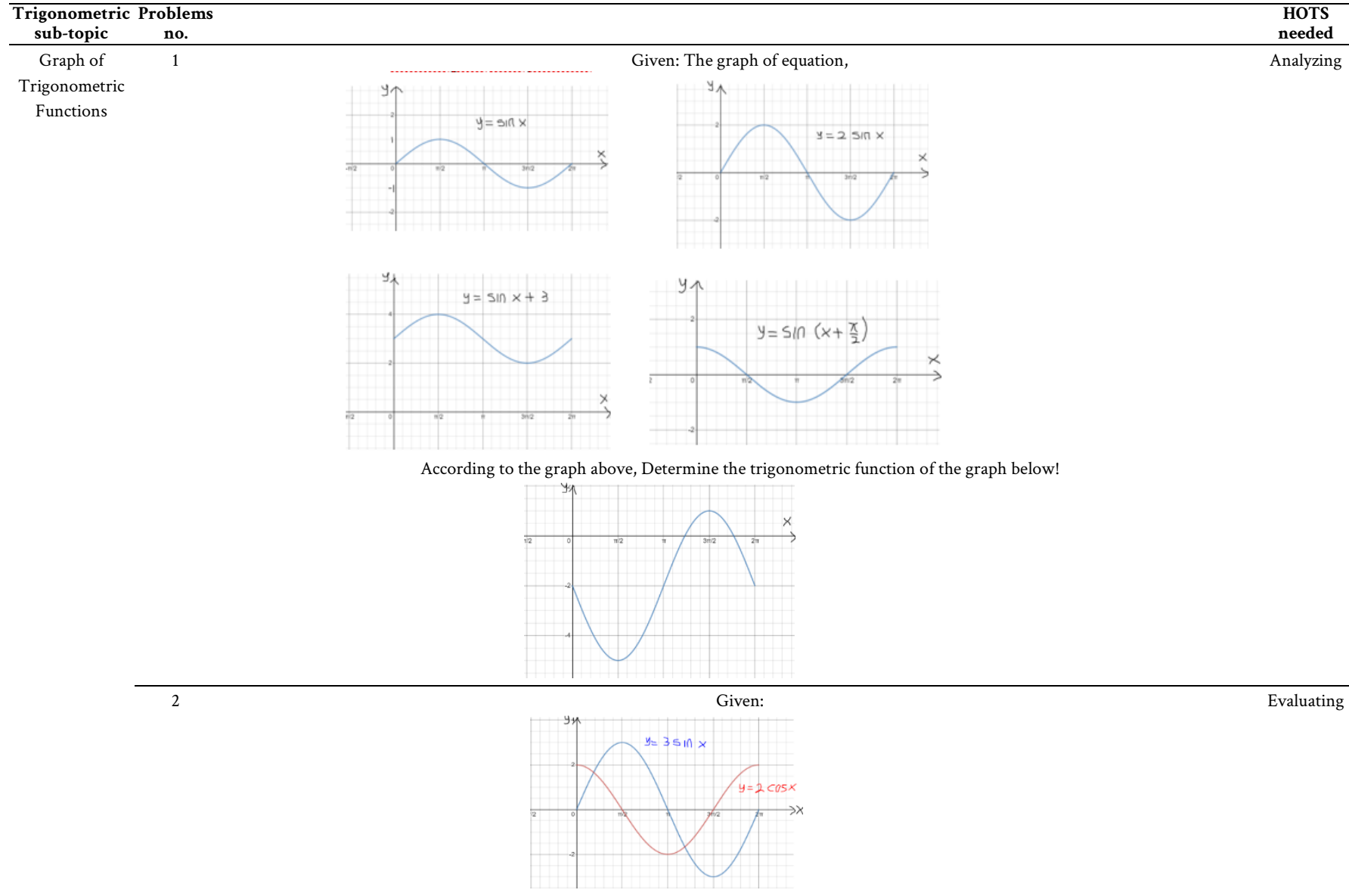

According to the graph, Berdasarkan grafik tersebut Does the graph below match with the trigonometric function? Please give your explanation! $y=3 \sin x-2 \cos x$

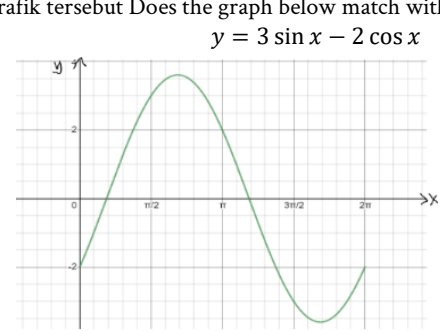

identities

Given: Trigonometry Identities Formula

Firman is asked to find the length of $d$. Let's help Fimran find the length of $d$ by using the trigonometric identities formula given.

$$
\begin{aligned}
& \sin (\alpha+\beta)=\sin \alpha \cos \beta+\cos \alpha \sin \beta \\
& \sin (\alpha-\beta)=\sin \alpha \cos \beta-\cos \alpha \sin \beta \\
& \cos (\alpha+\beta)=\cos \alpha \cos \beta-\sin \alpha \sin \beta \\
& \cos (\alpha-\beta)=\cos \alpha \cos \beta+\sin \alpha \sin \beta \\
& \tan (\alpha+\beta)=\frac{\tan \alpha+\tan \beta}{1-\tan \alpha \tan \beta} \\
& \tan (\alpha-\beta)=\frac{\tan \alpha-\tan \beta}{1+\tan \alpha \tan \beta}
\end{aligned}
$$

[Hint: Express $d$ as a function of $a, b$ and $c$ ]

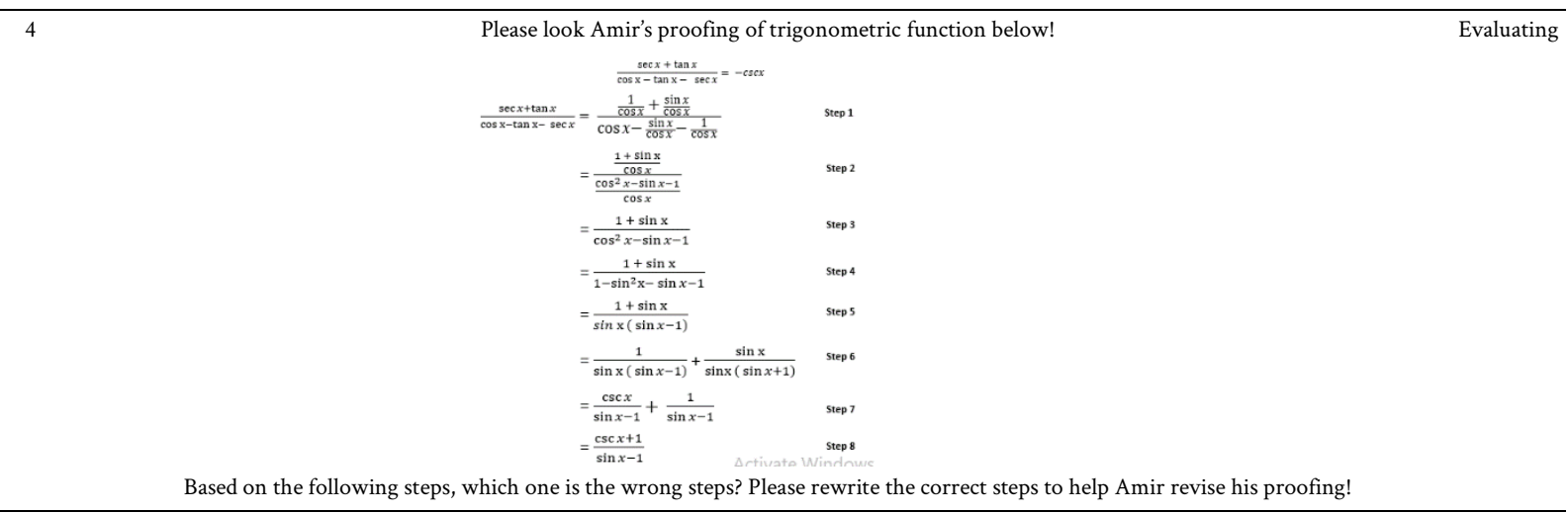


Table 4. The Question of the Interview Based on Interview Procedure of NEA

\begin{tabular}{lll}
\hline Level of Error & English Version & Indonesian Version \\
\hline Reading level & Can you read the problem? & Silakan kamu baca soalnya? \\
\hline Comprehension level & What does the question ask you to do? & Apa yang sebenarnya diminta soal? \\
\hline Transformation level & What do you use to solve the problem? & Strategi atau langkah apa yang kamu gunakan untuk menyelesaikan soal tersebut? \\
\hline Process Skills & $\begin{array}{l}\text { Can you show me the working steps that you have used in order to } \\
\text { find the solution? }\end{array}$ & Bisakah kamu tunjukkan langkah-langkah penyelesaiannya? \\
\hline Encoding & Tell me what is your answer? & Apa jawaban akhirmu? \\
\hline
\end{tabular}

Table 5. Summary of the students' general result

\begin{tabular}{|c|c|c|c|c|c|c|c|c|}
\hline & \multicolumn{2}{|c|}{ Problem 1} & \multicolumn{2}{|c|}{ Problem 2} & \multicolumn{2}{|c|}{ Problem 3} & \multicolumn{2}{|c|}{ Problem 4} \\
\hline & $\mathbf{n}$ & $\%$ & $\mathbf{n}$ & $\%$ & $\mathbf{n}$ & $\%$ & $\mathbf{n}$ & $\%$ \\
\hline Not answer & 5 & $14.7 \%$ & 7 & $20.6 \%$ & 11 & $32.3 \%$ & 1 & $2.9 \%$ \\
\hline Correct answer & 2 & $5.8 \%$ & 3 & $8.8 \%$ & 0 & $0 \%$ & 4 & $11.8 \%$ \\
\hline Incorrect answer & 27 & $79.5 \%$ & 24 & $70.6 \%$ & 23 & $67.7 \%$ & 29 & $85.3 \%$ \\
\hline
\end{tabular}

Table 6. Coding for Matrix Analysis

\begin{tabular}{|c|c|c|c|c|}
\hline \multirow{2}{*}{ Subject } & \multicolumn{2}{|c|}{ Analysis } & \multicolumn{2}{|c|}{ Evaluation } \\
\hline & Problem 1 & Problem 3 & Problem 2 & Problem 4 \\
\hline Q1 & Transformation Error & & & Process Skills Error \\
\hline Q2 & Transformation Error & & & Process Skills Error \\
\hline Q3 & Transformation Error & Transformation Error & & Process Skills Error \\
\hline Q4 & Transformation Error & Transformation Error & & Process Skills Error \\
\hline \multirow{2}{*}{ Q5 } & \multirow{2}{*}{ Transformation Error } & Comprehension Error & & \\
\hline & & Transformation Error & & \\
\hline Q6 & Transformation Error & Process Skills Error & Transformation Error & \\
\hline
\end{tabular}

instructions. Usually, this error is indicated by errors in answering "what does the question ask you to do?" and "what is given?" from the test. These errors purely regarding the information that students receive after reading the problem, it means they have not carried out the mathematics process yet. Based on Figure 3, one out of six students made an error in accepting what the question was asking in problem 3 , where he wrote $\sqrt{14}$ as the final result (the one being circled), whereas the information given stated that $d$ is a function of $a, b$, and $c$. It means that the students needed to construct $d$ equal to some expression written in terms of $a, b$, and $c$. The error was confirmed by the interviewed with Q5 as written below.

Q5: "Nilai d nya ketemu, Cuma gak tau betul gak tau salah, saya jawabannya $\sqrt{14}$,

[Translation] Q5: "I got it, but I do not know the answer was correct or not, I answered $\sqrt{14}$ ”

R: "Coba baca lagi soalnya."

[Translation] E: "Please re-read the question!"

Q5: Bantulah firman menemukan panjang d menggunakan rumus troigonometri identitas diatas, nyatakan d sebagai fungsi dari $a, b$, dan $c$

[Translation] Q5: "Let's help Firman to find the length of d by using trigonometry identities formula above. Express $\mathrm{d}$ as a function of $a, b$, and c"

\section{R: "Berarti nanti hasil akhirnya seharusnya gimana?"}

[Translation] R: "It means, the final answer should be?"

Q5: (Diam)

[Translation] S: (Silence...)
[Translation] R: "If we are asked to express in term of a, b, and c, means?"

Q5: "Harus persamaan"

[Translation] Q5: “The answer should be in term of equation”

By this interview result, the error was caused by two possibilities, Q5 did not understand the instruction or based on carelessness of due to the stress of the test. However, from how Q5 silence when the researcher re-asked his understanding about the question, it can be concluded that Q5 did not understand the question of the problem.

\section{Transformation Error}

Transformation errors occur when the students understand the information given then carrying it out into appropriate mathematics strategy, but they are not able to select the right mathematical operation or formula in finding the result. This error is indicated by error in answering the question "what are the strategies that you use to find the result?”. Figure 4 is an example of transformation errors made by Q5 in solving problem 1 . It can be seen from how the students change the graph into mathematics operation. To find the amplitude, phase shift, period and vertical shift, Q5 used check and re-check strategy. It could be confirmed by the interview, where Q5 stated:

"Nyoba-nyoba nya gini, misalnya yang pertama $\frac{\pi}{2}$ itu adanya di -5 berarti kita harus cari, ini kan garfik $\sin x$, grafik $\sin x$ itu supaya -5 ditambah atau dikali berapa. Kan $\sin 90=1$ untuk -5 itu bisa ditambah-4 atau dikali-5”

[Translation] "I tried it, I mean like this. The first $\frac{\pi}{2}$ is in -5 , it means we have to find it, this is graph of $\sin x$, right? In order to make $\sin x$ become -5 , we can add or multiply $\sin x$ by something. $\sin \frac{\pi}{2}=1$, for -5 it can be added by -4 or multiplied by -5 . 


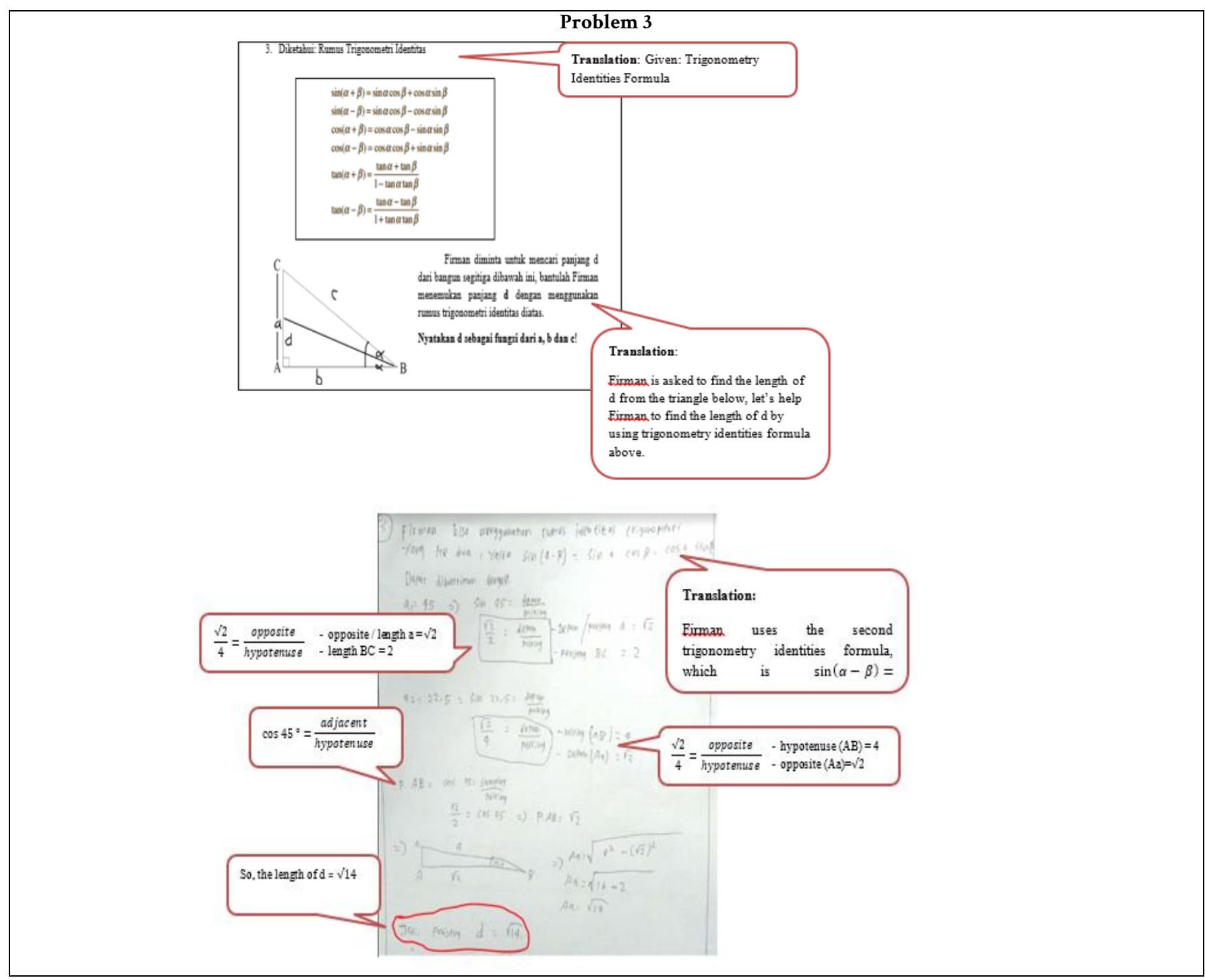

Figure 3. The Example of Comprehension Error by Q5

\section{Problem 1}
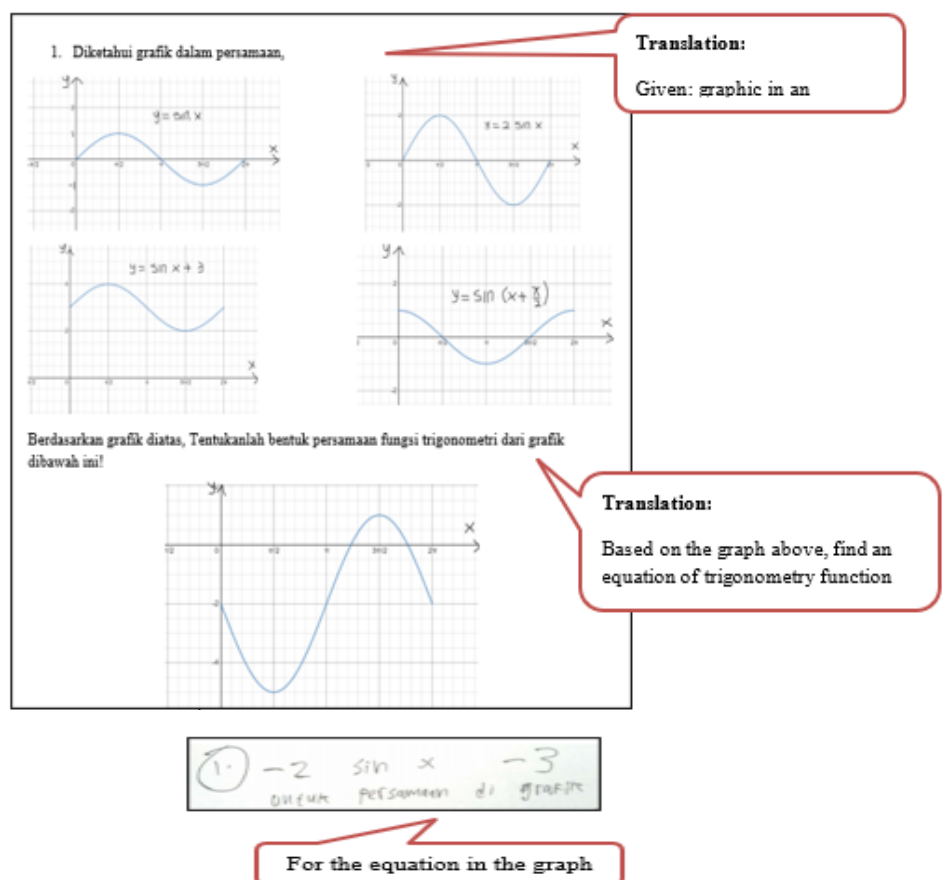

For the equation in the graph

Figure 4. The Example of Comprehension Error by Q5 


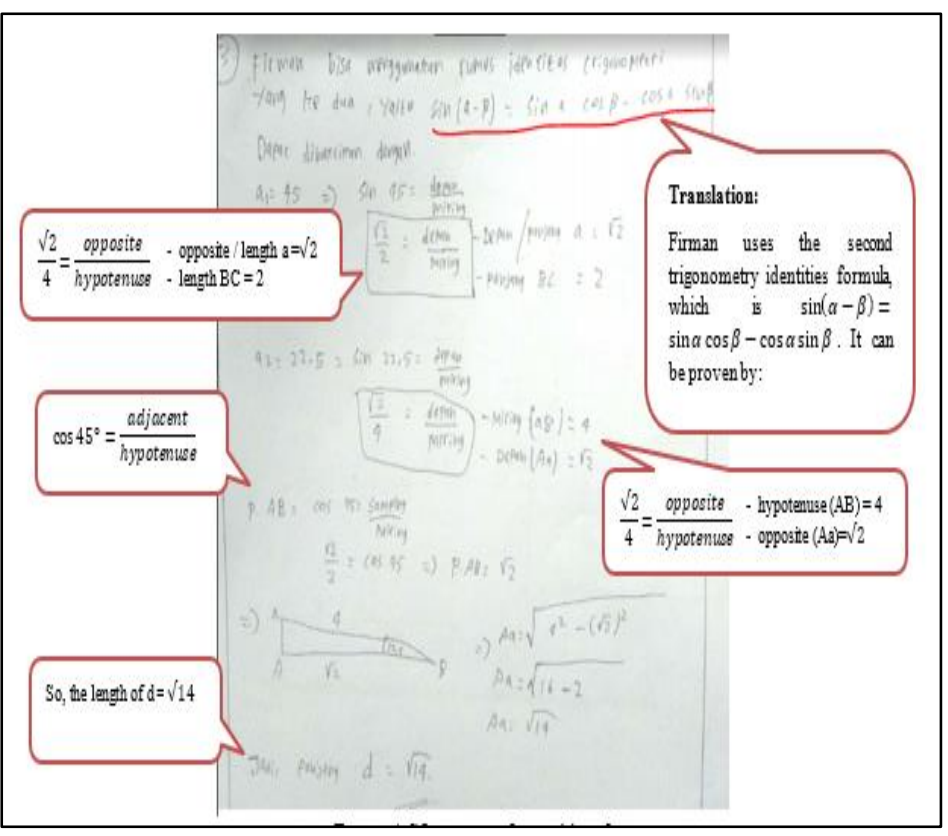

Figure 5. Q5 Response for Problem 3

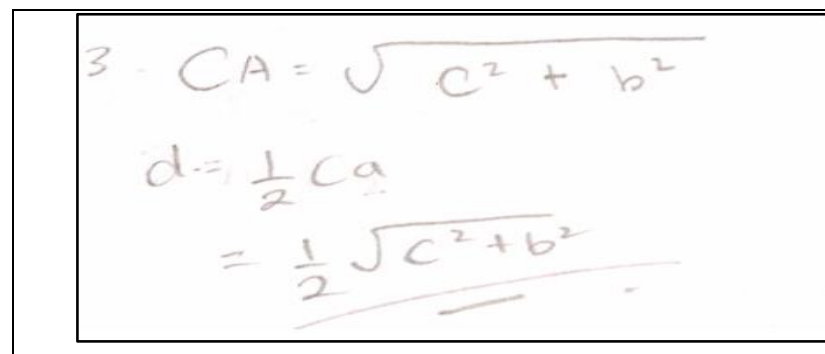

(a)

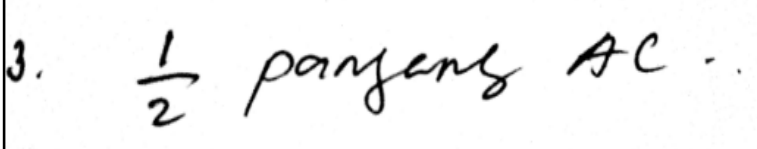

(b)

Figure 6. (a) Q4 Response for Problem 3 (b) Q3 Response for Problem 3

From this, Q5 add -2 and -3 to prove one of coordinate point on the graph is true (when $\mathrm{x}=\frac{\pi}{2}$ then $\mathrm{y}=-5$ ). Based on the analysis, Q5 did not know the role of -2 and -3 .

Another transformation error is also happening in problem 3. As shown in Figure 5, Q5 used the formula $\sin (\alpha-\beta)=\sin \alpha \cos \beta-$ $\cos \alpha \sin \beta$ to find the solution. Due to the value of $d$ as the opposite of $\alpha$, then Q5 thought that the value of $d$ would be easily found if he used that formula, as we know that $\sin \alpha=\frac{\text { opposite }}{\text { hypotenuse }}$. This was confirmed by the interview, where Q5 said:

"Karna sin ini langsung menuju ke jawaban, kan yang dicari d.d itu kalau di sin, misal sudut disini kalau sin kan depan/miring. Langsung ketemu depannya misalnya disini 45. Akar 2 sebagai depan, 2 nya sebagai sisi miring jadi gitu alasannya milih sin"

[Translation] "Because the sin indicated the answer, the value of d. For example, the angle of $\sin$ is $\frac{\text { opposite }}{\text { hypotenuse }}$. We can directly find the opposite, where the angle is 45 . The $\sqrt{2}$ as the opposite and 2 as the hypotenuse, so this is the reason why I chose sin".

Furthermore, Figure 6 shows Q3 and Q4 made a mistake in determining the formula, they show that the value of $\mathrm{d}$ is equal to $\frac{C A}{2}$ where $d$ is the half of CA. To find CA, Q4 used Pythagoras formula, she got $\mathrm{CA}=\sqrt{c^{2}+b^{2}}$. In determining $\mathrm{CA}, \mathrm{Q} 4$ also made a mistake, the $\sqrt{c^{2}+b^{2}}$ could only be used to calculate the value of CA when it is hypotenuse, whereas the formula should be $\sqrt{c^{2}-b^{2}}$. Based on the interview, Q4 did not understand about the formula of trigonometry identities so that she used Pythagoras formula to find the result.

\section{Process Skills Errors}

Process skills errors are referring to the error in calculating the operation, implementing mathematical problem, and recognizing the operation. This is becoming the most common error faced by the student, and it happened in the test. Most of the students have process skills errors were in problem 4 , where the information asked the students to find the wrong steps and rewrite the correct steps in detail. Figure 8 shows, Q4 got the error in recognizing the operation. Based on the interview, Q4 made an error in performing the trigonometric fraction operation. He answered the wrong step is from step 2. To revise the step, Q4 wrote $\frac{\frac{1+\sin x}{\cos x}}{\frac{\cos x-\sin x-1}{\cos x}}$ (step 2). Q4 thought that $\cos x-\frac{\sin x}{\cos x}-\frac{1}{\cos x}=\frac{\cos x-\sin x-1}{\cos x}$. From this error serves shows, Q4 knows that when there is subtracting fraction with unlike denominator, she has to find the common denominator. However, after found the common denominator, she just computed the numerator and retain the common denominator, whereas before it, she had to change $\cos x$ with equivalent fraction, which is $\frac{\cos ^{2} x}{\cos x}$. Furthermore, seeing closely at step 


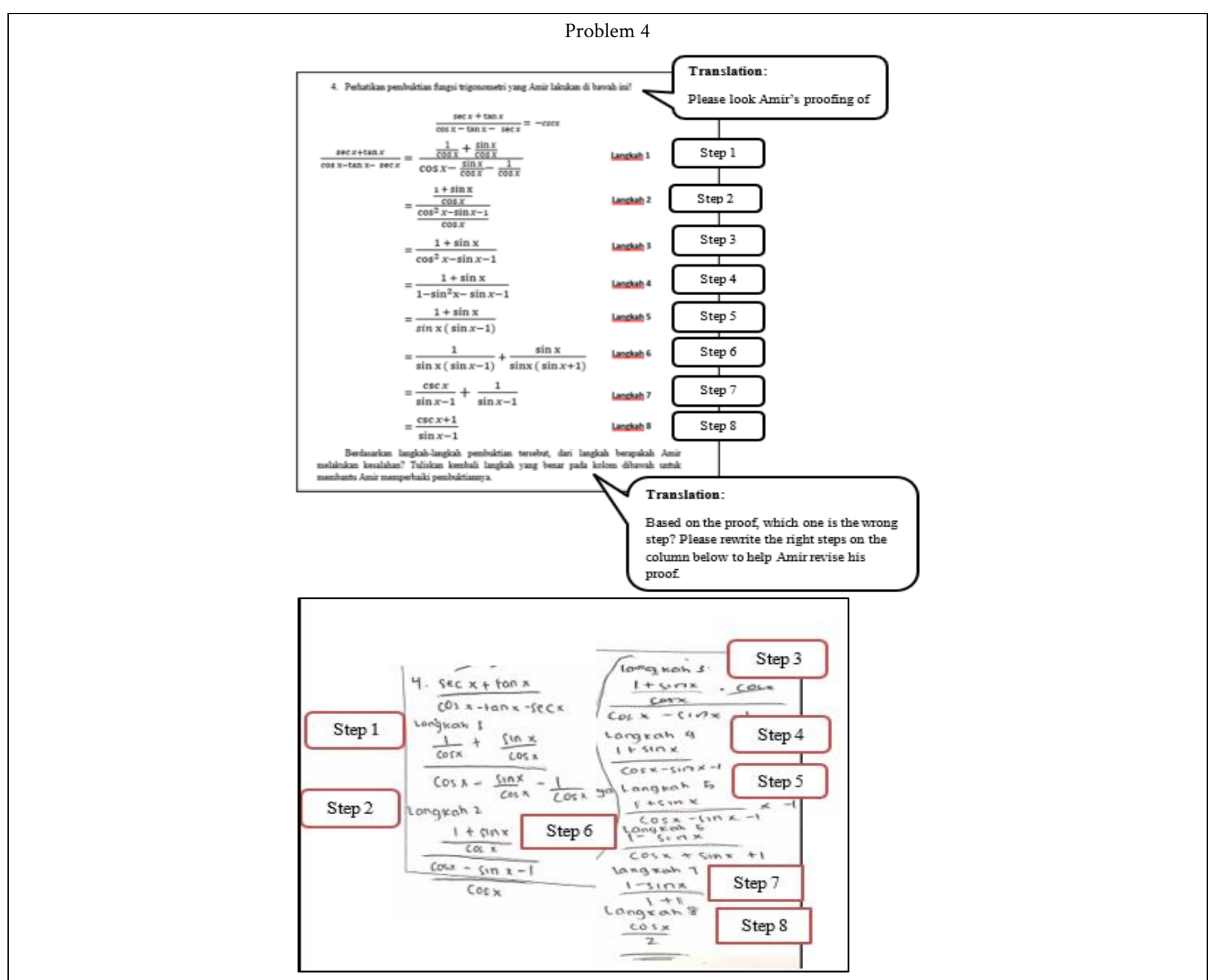

Figure 7. The Example of Q4 Response in Solving Problem 4

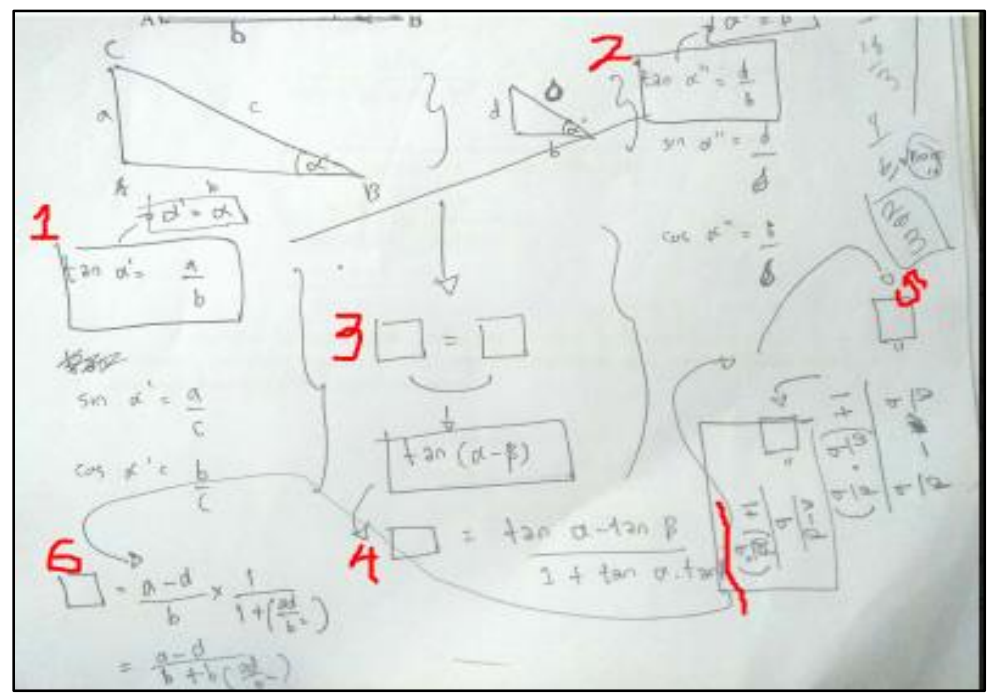

Figure 8. Process Skills Errors Made by Q6 in Solving Problem 3

5, the multiplication performed by Q4 also still error, where he tried to multiply the numerator and denominator with -1 to change the symbol (negative or positive). In addition, Q1 wrote $\frac{\frac{1+\sin x}{\cos ^{2} x}}{\frac{\cos ^{2} \sin x-1}{\cos ^{2} x}}$ (step 2), she knows that when there is addition fraction with the same denominator, she had to multiply the denominator, such as $\frac{1}{\cos x}+\frac{\sin x}{\cos x}=\frac{1+\sin x}{\cos ^{2} x}$.

Moreover, the error is also found in problem 3. In Figure 8 shows that Q6 almost find the result where he used $\tan (\alpha-\beta)=$ 
$\frac{\tan \alpha-\tan \beta}{1+\tan \alpha \tan \beta}$ formula to find d. Q6 already knows $\tan \alpha=\frac{a}{b}$ and $\tan \beta=\frac{d}{b}$, then he substitutes $\tan \alpha$ and $\tan \beta$ to the formula, so he got $\tan (\alpha-\beta)=\frac{a-d}{b+b \frac{a d}{b^{2}}}$. However, the error appeared because he did not pay attention to the angles. It can be seen when he did not let $\alpha=$ $2 \theta$ and $\beta=\theta$, so when there is $\tan (\alpha-\beta)$, he did not know that $\tan (\alpha-\beta)=\tan (2 \theta-\theta)=\tan \beta=\frac{d}{b}$. Therefore, in the last steps, he confused in finding the final result because he did not substitute $\tan (\alpha-\beta)$ be $\frac{d}{b}$.

\section{DISCUSSION}

The result shows SMAN X Karawang students have difficulties in comprehending the instruction, transforming the visual mathematics into mathematics representation, and recognizing the operation. These difficulties can be seen from the students' error that is exist when they solving the test. Meanwhile, the students do not have the error in reading the text and mathematics symbols. This finding is in line with the result of two researchers, Abdullah et al. (2015) and Santoso et al. (2017). In both studies shows that the subjects have good reading skills, so the errors were not encountered. However, they found encoding errors on their subjects' result.

There was one out of 6 students who have a problem to understand the instruction, the one is Q5. It appeared in problem 3 when the students were asked to find the length of $d$ in term of $a, b$ and c, where it is other variable given the problem. However, Q5 still answers $d$ as a value, which is $\sqrt{14}$. From the interview, I saw this student almost understand the instruction overall, but he did not understand to interpret the phrase "express $\mathrm{d}$ as a function of $\mathrm{a}, \mathrm{b}$, and c." It is similar with Carlson's finding, and he said this phrase is called as a function composition word problem (Carlson, Madison, \& West, 2010).

Another error was in students' performing transformation, where not all students were able to transforming the visual mathematics to mathematics representation. It can be seen from the students failed in carrying out their understanding of the problem to the mathematics formula they needed. From the test result, there were 3 out of 6 students used the wrong formula in solving problem 3. Two of them used Pythagoras formula to find $d$, whereas the instruction told that the students could choose one of the trigonometry identities formulas given. Based on the analysis and the interview, some of them thought that the length of $d$ is twice the length of AC, while the rest did not know how to solve the problem by using the trigonometric function formula.

Process of the problem is another error made by the students. It can be seen from students perform a trigonometric function operation and arithmetic skills. They mostly do the error when solving problem 4 , where the question asked the students to make a judgment validity of a proving identities, so the students need to algebraic manipulation into trigonometric expression. While doing it, they need to deal with the fraction with unlike denominator. However, there were two out of four students who are still confused in calculating the trigonometric fraction operation when facing unlike denominator, the one is Q4. For example, when $\cos x-\frac{\sin x}{\cos x}-\frac{1}{\cos x}$, Q4 wrote $\frac{\cos x-\sin x-1}{\cos x}$ as the result of the operation. It means, she has low basic mathematics in fraction, whereby she just computed the numerator and retain the common denominator. The students' error in manipulating trigonometric function which is presented in fractional form also appeared in Siyepu's study, such as applying lowest common denominator (LCD). Based on Siyepu (2015), it happens because the students have a poor simplification of fractional ability.

\section{CONCLUSION}

The objective of this study is investigating the students' error in solving trigonometric function problem, so the findings will only investigate the error, means it will not analyze the students higher order thinking skills. Based on the test and interviewed, there are three out of five categories of error that found: comprehension, transformation, and process skills. The common error was occurred in transform and process skills performing, where the students failed to transform the graph into equation and operate the fraction with unlike denominator.

This study is useful for the teachers in developing HOTS because it will help them in identifying and classifying possible difficulties in teaching HOT. Also, this study benefits for other researchers who are interest with trigonometric function, so it can be used as a reference. Beside teachers and researchers, it can help the government as they will get references in making exercise on the exam.

As a common study, this study has limitations. The participants are the students who have a good learning performance in 12th grade, making the first limitation. By selecting the participants, the findings will not appropriate to be generalize into other kind of participant, except for similar participant. The 12 grade students also are expected able to solve the problems easily because they were in preparing the National Examination (NE). Second, to measure HOTS, this study only focusing on two categories in Bloom's Taxonomy that are analyzing and evaluating. The reason why the last category (creating) is not used in this study because if three of HOTS level used with the duration is only 90 minutes, it is unfeasible to do in that short time.

From the limitations, the researcher needs another study to enrich the knowledge obtained by this study. Other future researchers can find the factors of these errors by observing the strategy that teachers used and analyzing the students' perspective about the problems given. This can be supported by the study that investigates students' error being influence by teaching strategies used.

\section{REFERENCES}

Abdullah, A. H., Abidin, N. L. Z., \& Ali, M. (2015). Analysis of students' errors in solving Higher Order Thinking Skills (HOTS) problem for the topic of fraction. Asian Social Science, 11(21), 133-142. https://doi.org/10.5539/ass.v11n21p133

Anderegg, Frederick and Edward Roe. (1896). Trigonometry for Schools and Colleges. Boston: Ginn and Co.

Ardina, I. (2018, April 20). Apa itu HIgher Order Thinking SKills (HOTS). Retrieved from http://beritagar.id/artikel/gaya-hidup/apa-ituhigher-order-thinking-skills-hots

Breidenbach, D., Dubinsky, E., Hawks, J., \& Nichols, D. (1992). Development of the process conception of function. Educational Studies in Mathematics, 23, 247-285. https://doi.org/10.1007/ BF02309532 
Carlson, M., Madison, B., \& West, R. (2010). The Calculus Concept Readiness (CCR) instrument: Assessing student readiness for calculus. arXiv preprint arXiv:1010.2719.

Chidozie, C. C., Libunao, W. H., Kamen, Y. B., \& Saud, M. S. B. (2014). Implementing higher order thinking skills in teaching and learning of design and technology education. TVEIS 2014, 633.

Creswell, J. W. (2012). Educational research: planning, conducting, and evaluating quantitative and qualitative research (4th ed). Boston: Pearson.

Erdogan, Vacide. (2005). Contribution of Error Analysis to Foreign Language 58 Teaching. Mersin University Journal of the Faculty of Education (Vol. 1).

Fi, C. (2003). Preservice Secondary School Mathematics Teachers' Knowledge of Trigonometry: Subject Matter Content Knowledge, Pedagogical Content Knowledge and Envisioned Pedagogy (Unpublished PhD Thesis), University of Iowa: USA.

Greenes, C., Chang, K. Y., \& Ben-Chaim, D. (2007). International survey of high school students' understanding of key concepts of linearity. In Proceedings of the 31st Conference of the International Group for the Psychology of Mathematics Education (Vol. 2, pp. 273280). PME.

Hadi, S., Retnawati, H., Munadi, S., Apino, E., \& Wulandari, N. F. (2018). The difficulties of high school students in solving higherorder thinking skills problems. Problems of Education in the 21st Century, 76(4), 520-532.

Heong, Y. M., Othman, W. B., Yunos, J. B. M., Kiong, T. T., Hassan, R. B., \& Mohamad, M. M. B. (2011). The level of marzano higher order thinking skills among technical education students. International Journal of Social Science and Humanity, 1(2), 121. https://doi.org/10.7763/IJSSH.2011.V1.20
Krathwohl, D. R. (2010). A revision of Bloom's Taxonomy: an overview. Theory into Practice, 41(4), 212-218. https://doi.org/10.1207/s15430421tip4104_2

Lewis, A., \& Smith, D. (1993). Defining higher order thinking. Theory into practice, 32(3), 131-137. https://doi.org/10.1080/ 00405849309543588

Ministry of Education and Culture. (2016). Regulation of the Minister of Education and Culture of the Republic of Indonesia Number 21 year 2016 on Standard Content of Primary and Secondary Education Units.

OECD. (2016). PISA 2015 results: Excellence and equity in education (Vol. 1). https://doi.org/10.1787/9789264266490-en

Sandelowski, M. (2000). Whatever happened to qualitative description?. Research in nursing $\&$ health, 23(4), 334-340. https://doi.org/10.1002/1098-240X(200008)23:4\%3C334::AIDNUR9\%3E3.0.CO;2-G

Sekolah Kita. (n.d.). Retrieved from http://sekolah.data.kemdikbud.go .id/index.php/chome/profil/2EA1E5A4-0BD0-4AFC-8A88AACFC0F827D2

Siyepu, S. W. (2015). Analysis of errors in derivatives of trigonometric functions. International Journal of STEM Education, 2(1), 16. https://doi.org/10.1186/s40594-015-0029-5

Spooner, M. (2002). Errors and misconceptions in maths at key stage 2. Working towards a successful SATs. London: David Fulton Publishers.

Stayanchi, J. (2017). Higher Order Thinking through Bloom's Taxonomy. Kwansei Gakuin University Humanities Review, 22, 117124.

Wegerif, R. (2002). Literature review in thinking skills, technology and learning. NESTA Futurelab series.

White, A. L. (2005). Active Mathematics in Classrooms: Finding out why children make mistakes-and then doing something to help them. Square One, 15(4), 15-19. 